\title{
The role of music preferences in early adolescents' friendship formation and stability
}

\author{
Maarten H.W. Selfhout ${ }^{a, *}$, Susan J.T. Branje $e^{a, 1}$, \\ Tom F.M. ter Bogt ${ }^{\mathrm{b}, 2}$, Wim H.J. Meeus ${ }^{\mathrm{a}, 3}$ \\ ${ }^{a}$ Research Centre Adolescent Development, Utrecht University, P.O. Box 80140, 3508 TC Utrecht, The Netherlands \\ ${ }^{\mathrm{b}}$ Department of General Social Sciences, Utrecht University, P.O. Box 80140, 3508 TC Utrecht, The Netherlands
}

\begin{abstract}
The present study examines the role of similarity in music preferences in the formation and discontinuation of friendships over a 1-year period. Questionnaire data were gathered from 283 Dutch same-sex mutual best friends (mean age $=12.97$ ) in two waves with a 1-year interval. Results show consistent evidence for high similarity in specific music dimensions among friends at both waves. Moderate similarity was found in the overall patterning of preferences for music genres at both waves, even after controlling for similarity in social background. Specific music similarity in more non-mainstream music dimensions and overall music similarity at Wave 1 were related to selecting a new friend at Wave 2. However, similarity in music preferences was not related to the discontinuation of an existing friendship at Wave 2. Thus, results suggest that similarity in music preferences is related to friendship formation, and not to friendship discontinuation.

(C) 2007 The Association for Professionals in Services for Adolescents. Published by Elsevier Ltd. All rights reserved.
\end{abstract}

Keywords: Music preferences; Friendship formation; Friendship stability; Early adolescence

\footnotetext{
*Corresponding author. Tel.: + $31302535844,+31647142994$; fax: + 31302537731 .

E-mail addresses: m.selfhout@uu.nl (M.H.W. Selfhout), s.branje@uu.nl (S.J.T. Branje), t.f.m.terbogt@uu.nl (T.F.M. ter Bogt), w.meeus@uu.nl (W.H.J. Meeus).

${ }^{1}$ Tel.: + 31302534039 ; fax: + 31302537731 .

${ }^{2}$ Tel:: + 31302534740 ; fax: + 31302537731 .

${ }^{3}$ Tel.: + 31302534890 ; fax: + 31302537731 .
}

0140-1971/\$30.00 @ 2007 The Association for Professionals in Services for Adolescents. Published by Elsevier Ltd. All rights reserved.

doi:10.1016/j.adolescence.2007.11.004 


\section{Introduction}

During adolescence, music becomes increasingly important in the personal and social lives of adolescents (Arnett, 1991; Ter Bogt, Raaijmakers, Vollebergh, Van Wel, \& Sikkema, 2003). From early adolescence onwards, an increasing amount of time and money is spent on music affairs (Christenson \& Roberts, 1998; Sikkema, 2005). Music preferences may play an important role in early adolescent interaction with peers, as music is listened to and shared with friends (Christenson \& Roberts, 1998) and peer crowds often center around certain musical preferences (Arnett, 1991; Bennet, 2001; Urberg, Degirmencioglu, Tolson, \& Halliday-Scher, 2000). Although one study showed that similarity in music preferences plays an important role when undergraduates were given the task of getting acquainted (Rentfrow \& Gosling, 2006) and it has been suggested that this process may be even stronger for early adolescents (Rentfrow \& Gosling, 2007; Ter Bogt, 2004), research on the role of music preferences in the formation and maintenance of early adolescents' best friendships is seriously lacking. The present study examines similarity in music preferences in early adolescents' mutual friendships and the longitudinal role of this similarity in the formation and stability of these friendships.

\section{Similarity in music preferences in adolescent friendships}

Why would similarity in music preferences play an important role in early adolescent friendships? Several theoretical frameworks suggest that sharing musical preferences may be important in social relationships. First, several researchers (Tarrant, North, \& Hargreaves, 2001) have applied Social Identity Theory (SIT; Tajfel, 1978) to the use of music preferences in individuals' identity within peer groups. SIT maintains that individuals gain a social identity from the groups to which they belong and will therefore adopt similar preferences and habits to those of the individuals in their group in an attempt to foster self-esteem and feelings of belonging. As adolescent musical preferences often form the core of peer cliques and groups (Brown, Eicher, \& Petrie, 1986) and a musical preference is a valued and important dimension of adolescents' social identity (Tarrant et al., 2001), this perspective suggests that adolescent friends have similar music preferences since friends adopt each others preferences.

Second, the similarity-attraction hypothesis (e.g., Byrne, 1971) and the perspective of assortative mating (Luo \& Klohnen, 2005) suggest that individuals are most attracted to other people who have similar attitudes and values (e.g., Fehr, 2001), behaviors (e.g., Tolson \& Urberg, 1993), and personality characteristics (Morry, 2005), and will select these similar others as friends and romantic partners. The "filtering" perspective of Duck and Craig (1978) uses the similarityattraction hypothesis to suggest that directly observable information about other individuals provides the initial filter in the formation of friendships. As friendships progress, directly observable information is suggested to become less important in the stability of friendships. Since music preferences of early adolescents are often directly visible through clothing, hair style, and outward behavior associated with a music genre (Christenson \& Roberts, 1998; Ter Bogt, 2000), similarity in music preferences can be expected to have an important role in the formation of best friendships. More specifically, music preferences of early adolescents provide unique visible cues concerning one's personality, life style, and values, and music preferences may therefore be used to select new friends (Rentfrow \& Gosling, 2006, 2007). 
Thus, adolescent friends are suggested to be similar in musical preferences since they select friends with similar music preferences and adopt their friends music preferences, respectively. In addition, the filtering perspective and the perspective of Rentfrow and Gosling suggests that similarity in music preferences may be especially important in adolescent friendship formation. Finally, the filtering perspective suggests that similarity in music preferences is less important in the instability of friendships.

Several studies examined similarity in music preferences between individuals. In a survey among college students (Rozin, Riklis, \& Margolis, 2004), no differences were found in correlations of music preferences among self-selected roommates $(r=.30)$ and randomly paired roommates $(r=.17)$. Although this difference did not reach statistical significance, this may be due to the small sample size ( $n=10$ for self-selected roommates). Furthermore, the relationship between roommates is likely to be more superficial than the relationship between best friends. In an experimental study, Knobloch, Vorderer, and Zillmann (1999) showed that when adolescents perceive higher similarity in music preferences with a random adolescent, they have a higher desire to become "good friends" and share activities with this random adolescent. One study showed that music is the most common topic in conversations among unacquainted undergraduates given the task of getting acquainted (Rentfrow \& Gosling, 2006). Furthermore, strangers' perceptions of music preferences of each other were quite accurate and specific music preferences were found to be linked to specific personality traits (Rentfrow \& Gosling, 2006, 2007). In addition, perceived music preferences correlated differently with personality, values, and personal quality than other cues, such as appearance, suggesting that music preferences provide unique cues during acquaintance processes (Rentfrow \& Gosling, 2006). Thus, although these studies did not examine best friendships, they provide some evidence for an important role of similarity of music preferences in social networks.

Dutch adolescents' music preferences can be clustered into four main music dimensions (Delsing, Ter Bogt, Engels, \& Meeus, 2007; Ter Bogt et al., 2003), namely Elite Dimensions, Rock Dimensions, Popular/Dance Dimensions, and Urban Dimensions. Each of these four music dimensions consist of specific music genres, e.g., classical music, heavy metal music, pop chart music, and hip-hop music, respectively. This pattern of four dimensions has been cross-validated in different samples in the Netherlands (Ter Bogt et al., 2003). Furthermore, these dimensions show close resemblance to four music-dimensions dimensions found in the United States (Rentfrow \& Gosling, 2003). Similarity in specific music dimensions is labeled specific music similarity. Adolescents' musical taste can not only be considered as preferences for a specific music dimensions, but also as a pattern across all the music genres. For example, groups with differential patterns across the four mentioned dimensions were found among 12- to 24-year-old adolescents and adults: whereas some adolescents like all music genres, others prefer only one genre and dislike other genres, and other adolescents may like only two specific genres (Ter Bogt et al., 2003). Similarity in the overall pattern of music genres is labeled overall music similarity.

\section{The present study}

The present study will first examine the extent to which friends are similar in specific and overall music similarity. In addition, the present study examines to what extent similarity in music preferences predicts the selection of new friend as well as whether friends continue being friends or 
discontinue being friends over a 1-year period. This was made possible since the two waves of the study allowed categorization of friends who did not nominate each other in Wave 1, but did at Wave 2 (to-be friends), friends who nominated each other at both waves (stable friends), and friends who did nominate each other at Wave 1, but not anymore at Wave 2 (unstable friends). This way, we will study the role of music preferences in the formation and instability of early adolescents' best friendships, respectively. Following suggestions of prior research, we expect that similarity in music preferences especially plays an important role in the formation of friendships, and less so in the instability of friendships.

The focus of the current study will be only on the first nominated best friend, since previous research has shown that this dyadic relationship is much stronger than other types of friendship (i.e., other close friends, such as the second or third nominated friends) (Degirmencioglu, Urberg, Tolson, \& Richard, 1998; Newcomb \& Bagwell, 1995). Additionally, first nominated friends seem to be the primary locus of influence on adolescents' school achievement and drug use (Mounts \& Steinberg, 1995). Finally, the stability of first nominated best friendships is much higher compared to other friendships (Berndt \& Keefe, 1995). Only mutual best friendships, or friendships in which both adolescents nominate each other as best friend, will be included, because mutual best friendship nominations seem to indicate stronger ties between friends than non-mutual best friendship nominations (Griffon-Smith \& Brownwell, 2003; Kurdek \& Krile, 1982).

To summarize, the current study tests the following hypotheses:

Hypothesis 1. Friends will show similarity in preferences for specific music dimensions and in the overall patterning of music preferences.

Hypothesis 2. Specific and overall music similarity predict friendship formation.

Hypothesis 3. Specific and overall music preferences do not predict friendship stability.

\section{Method}

\section{Participants}

Participants in this study were 566 adolescents of the early adolescent cohort participating in the CONflict And Management Of RElationships study (CONAMORE) (Meeus et al., 2004). CONAMORE is an ongoing longitudinal study that examines the relationships of Dutch adolescents with parents and peers as well as their emotional states. In the current study, data were used from the first two waves with a 1-year interval. Adolescent nominated a single best friend and were selected if their best friend participated in the study and if they could be coupled to their best friend nomination in the same dataset in one of the two measurement waves. Out of 940 adolescents, 566 selected adolescents formed 283 same-sex friendship dyads, consisting of $49.2 \%$ boys and $50.8 \%$ girls. Nine mixed-sex dyads were identified but this number was too small for inclusion in analyses. The mean age of all adolescents was 12.97 (S.D. = 1.58). All dyads were unique: no member of any dyad was also a member of another dyad at the same wave. The total group and the selected group of adolescents showed no significant $(p>.05)$ differences in gender, age, educational level, and all four music dimensions at both waves. 
The ethnic composition of the present sample was $88.1 \%$ Dutch and $11.9 \%$ ethnic minorities. $40.5 \%$ of the adolescents were in high schools preparing for lower level tertiary education or lower level jobs, and 59.5\% were in high schools preparing for college or university.

\section{Procedure}

Participants came from various high schools in Utrecht and surroundings. Parents and students received a letter in which the aims of the study were described and information was given about the option of not participating. Students were required to provide written informed consent. Less than $1 \%$ decided not to participate. Participants completed a series of questionnaires in their classroom after school hours. Research assistants, who attended the administration, gave verbal instructions about filling out the questionnaires; written instructions were also included. Confidentiality of their given answers was guaranteed explicitly. For students who were absent on the day of testing, a second assessment time was organized. Students who were absent on both days of testing were not assessed. Each wave, respondents received $€ 10$, after completing the questionnaires.

\section{Types of friendships}

Friendships were assessed by asking each respondent to nominate one single best friend who was not a brother or sister and not someone they had an intimate relationship with. Next, if these nominated best friends participated in the study and nominated the target adolescent as their best friend, they were coupled with the target adolescent. This resulted in 179 mutual best friendship dyads at Wave 1, and 162 mutual best friendship dyads at Wave 2, respectively. Of the 179 mutual best friends at Wave 1, 58 dyads stayed mutual best friends at Wave 2 (stable friends): that is, both adolescents nominated each other as mutual best friend 1 year later. The other 121 dyads did not nominate each other as mutual best friends at Wave 2, but did at Wave 1 (unstable friends). Furthermore, 104 to-be best friends were identified, consisting of dyads that nominated each other as mutual best friends only at Wave 2, and not at Wave 1.

\section{Measures}

Adolescents' music preferences were assessed by means of the Music Preference Questionnaire (MPQ; Sikkema, 1999). The MPQ consists of a list of 13 established categories of music. The items of the scale represent the major music dimensions in contemporary music. Subjects were asked to indicate on five-point Likert scales $(1=$ very bad, $5=$ very good $)$ the extent to which they liked each of the music genres listed. Missing data on the items of the questionnaires were imputed using the EM algorithm within SPSS 12.0. Four music dimensions were identified (see also Delsing et al., 2007): the Elite Dimensions is defined by the genres classical, gospel, and jazz; The Rock Dimensions is defined by rock, punk, gothic, and heavy metal music; The Popular/Dance Dimensions is defined by pop music/charts, trance, and clubhouse; The Urban Dimensions is defined by $\mathrm{rap} /$ hip-hop, $\mathrm{R} \& \mathrm{~B}$, and reggae. At both waves, exploratory factor-analyses on the present friendship sample clearly showed this four-factor solution, with few cross-loading genres. Furthermore, confirmatory factor analyses (CFA) showed that in models examining four-factor 
solutions in which each specific item loaded on corresponding factors, high factor loadings $(>.52)$ as well as adequate fit indices were found $\left(X^{2}(59, n=179 / 162)>56.19, p<.01\right.$; CFI's $>.98$, RMSEA's <.04). Cronbach's alpha's of the four dimensions were .69, .89, .64, and .79, respectively, at Wave 1 and .66, .91, .61, and .77, respectively, at Wave 2.

\section{Strategy of analysis}

In order to determine whether adolescents were more similar to their best friends in their preferences for specific music dimensions than to random non-friend dyads, multi-level intra-class correlations of each of the four music dimensions preferences were computed for friendship dyads. With this technique, a comparison group is not needed because this measure takes into account any similarity that may exist among random dyads. In order to compare similarity in stable best friendships and unstable best friendships, differences in intra-class correlations were tested for significance by a procedure suggested by Haggard (1958): intra-class correlations are transformed using Fisher's $z$ transformation, and then $Z$ is computed as the difference between the two intra-class correlations, divided by the standard error of difference. Finally, sex differences between intra-class correlations were explored.

To examine similarity in the overall patterning of music preferences, q-correlations, or profile correlations, were computed for mutual friendship dyads (Luo \& Klohnen, 2005). Q-correlations capture each dyad's similarity in terms of their organization (or patterning) of responses. Other types of similarity indexes, such as intra-class correlations and difference scores, are computed on the overarching "scale level" rather than on the individual "item level". That is, they completely ignore agreement (or disagreement) on the many specific responses on which the profile of individuals' music preferences is based, thus discarding a substantial amount of information that is captured by profile similarity correlations. Furthermore, in contrast to intra-class correlations, each dyad gets one q-correlation pertaining to their similarity in overall music genres and therefore this similarity score can be used to predict whether a friend is selected and whether a mutual friendship continues over a 1-year period. Thus, overall music similarity was based on the pattern of adolescents' scores on all 13 music genres compared to the pattern of their friends' scores on all 13 music genres.

Q-correlations do not account for the similarity that is found between random dyads, so overall music similarity will be examined by using a large number of randomly assigned dyads from a heterogeneous sample of adolescents to establish a base against which similarity in real best friendship dyads can be compared. Randomization was used to create random pairs at Wave 1 and Wave 2 separately. The adolescent target group that could be matched to a best friend ( $N=358$ and 324 at Wave 1 and Wave 2, respectively) was randomly assigned a 100 times to the adolescents who could not be matched to a friend within the total sample of the same age cohort ( $N=582$ at Wave 1 and $N=616$ and Wave 2). Multivariate tests on gender, age, educational level, and all four music dimensions showed no significant differences between the best friend sample and the random sample. Because all friendship dyads were same-sex, of a small age range (11-13), and had the same educational level, the random dyads were matched on gender, age, and educational level. Therefore, differences in overall music similarity between the real friends and the random dyads cannot be explained by the fact that best friends are more similar in 
background (i.e., gender, age, or educational level) than random dyads. In these analyses, the main effect of gender and educational level was controlled for.

\section{Results}

\section{Descriptives}

A repeated measure analysis of variance in which all four dimensions at both waves were included revealed that overall, the means between all four music dimensions on both waves differed significantly from each other $(F(7,276)=52.63, p<.001)$. As shown in Table 1 , the dimension Popular/Dance was rated significantly higher than all other dimensions at both waves, suggesting that this dimension is most popular among adolescents of the current sample. Next, Urban is liked the most, followed by both Elite and Rock, which are liked to the same extent. These last three dimensions can be seen as the less mainstream dimensions, since an average of three indicates that a dimension is neither liked or disliked. Finally, the Popular/Dance dimension becomes more popular over time, Urban and Rock become less popular over time, and Elite seems to be liked to the same extent at Wave 1 and Wave 2.

\section{Similarity in music preferences}

\section{Specific music similarity}

To examine specific music similarity among mutual best friends, intra-class correlations were computed for all four music dimensions. These results are shown in the first two columns of Table 2. At both waves, mutual best friends showed significant and high intra-class correlations on all four specific music dimensions, showing they are more similar in preferences for specific music dimensions than random dyads. Thus, these results confirm the first part of Hypothesis 1: Friends consistently show high similarity in specific music dimensions.

\section{Overall music similarity}

To examine overall music similarity, q-correlations were computed for friendship dyads and random dyads. Differences in mean similarity were assessed with an ANOVA, in which gender

Table 1

Descriptives of specific music dimensions for Wave 1 and Wave 2

\begin{tabular}{llrlrr}
\hline Specific music dimensions & \multicolumn{2}{l}{ Wave 1 $(n=179)$} & & \multicolumn{2}{l}{ Wave 2 $(n=162)$} \\
\cline { 2 - 3 } \cline { 5 - 6 } & $M$ & & & $M$ & S.D. \\
\hline Rock & $2.27^{\mathrm{a}}$ & 1.03 & & $2.13^{\mathrm{b}}$ & 1.05 \\
Elite & $2.38^{\mathrm{a}}$ & .93 & & $2.39^{\mathrm{a}}$ & .97 \\
Popular/Dance & $3.17^{\mathrm{b}}$ & .89 & $3.24^{\mathrm{c}}$ & 1.02 \\
Urban & $2.58^{\mathrm{d}}$ & .87 & $2.44^{\mathrm{e}}$ & 1.07 \\
\hline
\end{tabular}

Note: Differences between superscripts indicate significant $(p<.05)$ differences between means. 
Table 2

Intra-class correlations for all mutual best friendships, to-be friends, stable friends, and unstable friends

\begin{tabular}{lllllll}
\hline $\begin{array}{l}\text { Specific music } \\
\text { dimensions }\end{array}$ & Total friends & & To-be friends & $\begin{array}{l}\text { Stable } \\
\text { friends (1) }\end{array}$ & $\begin{array}{l}\text { Unstable } \\
\text { friends (2) }\end{array}$ & 1 vs. 2 \\
\cline { 2 - 3 } & $\begin{array}{l}\text { Wave } 1 \\
(n=179)\end{array}$ & $\begin{array}{l}\text { Wave } 2 \\
(n=162)\end{array}$ & $\begin{array}{l}\text { Wave } 1 \\
(n=104)\end{array}$ & $\begin{array}{l}\text { Wave } 1 \\
(n=58)\end{array}$ & $\begin{array}{l}\text { Wave } 1 \\
(n=121)\end{array}$ & \\
\hline Rock & $.55^{* *}$ & $.60^{* *}$ & $.31^{* *}$ & $.53^{* *}$ & $.54^{* *}$ & n.s. \\
Elite & $.36^{* *}$ & $.48^{* *}$ & $.34^{* *}$ & $.48^{* *}$ & .23 & n.s. \\
Popular/Dance & $.41^{* *}$ & $.48^{* *}$ & .16 & $.36^{* *}$ & $.44^{* *}$ & n.s. \\
Urban & $.42^{* *}$ & $.41^{* *}$ & $.22^{* *}$ & $.45^{* *}$ & .19 & n.s. \\
\hline
\end{tabular}

$* * p<.01$.

( $0=$ male, $1=$ female $)$, age, educational level $(0=$ low, high $=1)$, and dyad membership $(0=$ random dyad, $1=$ friend dyad $)$ were used to predict overall music similarity. At both waves, overall music similarity as indicated by mean q-correlations was significantly higher for friends ( $M=.31$ and $M=.38$ at Wave 1 and Wave 2 , respectively) than for random dyads ( $M=.04$ and $M=.03$ at Wave 1 and Wave 2, respectively), even after controlling for demographical background and similarity in demographical background. These results therefore confirm the second part of Hypothesis 1: Friends are moderately similar in their overall patterning of preferences for music dimensions.

\section{Similarity in music preferences in the formation of friendships}

\section{Specific music similarity}

To examine its role in friendship formation, specific music similarity on Wave 1 was computed for dyads that would become friends 1 year later (to-be best friends). Results are shown in Table 2, third column. Intra-class correlations on the music dimensions Rock, Elite, and Urban were significant and positive, indicating that dyads that were going to be friends 1 year later already showed more similarity than random dyads. No evidence was found for similarity in the music dimension Popular/Dance. Thus, these results partly confirm the first part of Hypothesis 2: specific music similarity in the more non-mainstream music dimensions is related to the formation of friendships.

\section{Overall music similarity}

To examine the role of similarity in the overall patterning of music preferences in friendship formation, a logistic regression analysis was performed using gender, educational level, overall music similarity, and interaction of gender and educational level with overall music similarity on Wave 1 to predict friendship formation at Wave $2(0=\operatorname{random}$ dyad, $1=$ to-be friend dyad $)$. Results are shown in Table 3, first two columns. Higher overall music similarity and the interaction between educational level and overall music similarity predict a higher chance of becoming a friend at Wave 2: adolescents who are more similar in overall music preferences have a 1.9 times higher chance of becoming friends than adolescents who are less similar in overall music preferences. Furthermore, adolescents with a higher educational level who are more similar in 
Table 3

Summary of logistic regression analyses: overall music similarity predicting friendship formation and friendship stability

\begin{tabular}{llllll}
\hline & \multicolumn{2}{l}{ To-be friends vs. random } & & \multicolumn{2}{l}{ Stable vs. unstable } \\
\cline { 2 - 3 } & OR & & & OR & \multicolumn{1}{c}{$B$} \\
\hline Similarity music & $1.9^{* *}$ & .64 & & 0.9 & -.02 \\
Similarity music gender & 1.1 & .09 & & 0.8 & -.20 \\
Similarity music educational level & $1.6^{*}$ & .49 & & 0.9 & -.07 \\
Gender & 1.4 & .32 & & 0.9 & -.15 \\
Educational level & 1.1 & .12 & & $1.5^{*}$ & .42 \\
\hline
\end{tabular}

$* p<.05$.

$* * p<.01$.

overall music preferences have a 1.6 higher chance of becoming friends compared to adolescents with a lower educational level who are more similar in overall music. It must be mentioned that adolescents with a higher educational level also had significantly $(p<.05)$ higher variances in overall music similarity that adolescents with a lower educational level (S.D. $=.68$ vs. .31 , respectively), suggesting that adolescents with a higher educational level have a more differentiated music taste than adolescents with a lower educational level. Thus, in agreement with the second part of Hypothesis 2, similarity in the overall patterning of music preferences predicts a higher chance of becoming friends 1 year later, even after controlling for demographical background and similarity in demographical background. Furthermore, for adolescents with a higher educational level, chances of becoming friends due to overall music similarity were higher than for adolescents with a lower educational level.

\section{Similarity in music preferences in the stability of friendships}

\section{Specific music similarity}

To examine the role of specific music similarity in friendship stability, specific music similarity was computed separately for stable friends and for unstable friends at Wave 1. Results are shown in Table 2, last three columns. Although stable friends showed higher intra-class correlations than unstable friends on the music dimensions Elite and Urban, none of the differences between stable friends and unstable friends were significant. These results show that specific music similarity does not play a role in the stability of friendships.

\section{Overall music similarity}

To examine the role of similarity in the overall patterning of music preferences in the stability of friendship, a logistic regression analysis was performed using gender, educational level, overall music similarity, and interaction of similarity in gender and educational level with overall music similarity at Wave 1 to predict friendship stability at Wave $2(0=$ unstable friends, $1=$ stable friends). Results are shown in Table 3, last two columns. Adolescents with a higher educational level have a 1.5 times higher chance of staying friends than adolescents with a lower educational level. When comparing standardized regression coefficients in this equation, the effect of 
educational level is larger than all other effects. Thus, these results suggest that similarity in the overall pattern of music preferences plays no role in friendship stability.

\section{Discussion}

The goals of the present study were to study friendship similarity in specific music styles and overall patterning of music preferences among friends and the role of this similarity in the formation of friendships and the stability of friendships, while controlling for similarity in social background. As expected, results provide clear and consistent evidence for high specific music similarity and moderate overall music similarity in early adolescent' mutual friendships. More importantly, both similarity in specific music dimensions and similarity in overall music preferences were found to be higher among mutual friends than among randomly paired adolescents, suggesting that early adolescents are more similar in specific music dimensions and overall music preferences to their friends than they are to other adolescents. These results are consistent with two theoretical frameworks. First, the Social Identity Theory (Tajfel, 1978) suggests that individuals may gain a social identity from the music-based groups to which they belong and will therefore adopt similar music preferences to those of the individuals in their group in an attempt to foster self-esteem and feelings of belonging (Tarrant et al., 2001). Second, the similarity-attraction hypothesis (e.g., Byrne, 1971) and the assortative mating perspective (Luo \& Klohnen, 2005) suggest that individuals are most attracted to other people who have similar attitudes, values, and behaviors, and personality characteristics: the current study suggests that this also applies to similarity in musical preferences.

Regarding the role of similarity in best friendship formation and stability, we adopted the perspectives of both Duck and Craig (1978) and Rentfrow and Gosling (2006, 2007), according to which similarity in music preferences predicts friendship formation since music preferences are made visible through clothing, hairstyle, and outward behavior, and individuals consider them as unique sources of visible information concerning personality, lifestyle, and values, respectively. In line with this hypothesis, results provide evidence for a role of both overall music similarity and specific music similarity in the dimensions that are more non-mainstream in the formation of mutual friendships. For three of the four specific music dimensions, namely Rock, Elite, and Urban, early adolescent dyads that would select each other as friends one year later were found to be more similar than adolescents from the same sample that did not select each other as friend. The music dimension Popular/Dance may not be a distinctive marker for early adolescent' mutual friendship selection because it is such a broadly accepted and consumed dimension, especially in early adolescence (Ter Bogt et al., 2003). Results of the present study confirm that it is the most popular dimension among early adolescents. Clothes, hairstyles, and outward behavior associated with more non-mainstream music dimensions can be used to clearly differentiate between adolescents (Ter Bogt, 2004) and may therefore play a role in mutual friendship formation. High similarity in the overall patterning of music preferences predicted a 1.9 times higher chance of becoming mutual friends one year later compared to random dyads, even when controlling for gender, educational level, and similarity in these background variables. The present findings are in line with previous findings that showed that perceived similarity in music preferences are related to friendship aspirations (Knobloch et al., 1999). Thus, similarity in music 
preferences seems to play an important role in the formation of early adolescent mutual friendships.

We also tested whether similarity in music preferences plays a role in friendship stability. Consistent with the filtering perspective, no evidence was found for a relationship between specific and overall music similarity and friendship stability. Music similarity therefore is related to mutual friendship formation, but not to mutual friendship stability. What do these results mean? It seems that during the formation process of early adolescents' friendships, music preferences seem to work as an important criterion to select one's friend because they tell a person something about one's potential friends' personality, life-styles, and values (Rentfrow \& Gosling, 2007; Ter Bogt, 2000). However, once friendships have been formed, they do not break up because of changes in music preferences. More likely, music preferences stay the same after the break-up of the friendship. Perhaps characteristics of the friendship itself, such as quality of friendship (e.g., Bagwell \& Coie, 2004) or conflicts between friends (Laursen, 1993) determine whether friendships are terminated. However, stable friends did show higher specific music similarity in Elite and Urban music dimensions than unstable friends and differences may have not reached significance due to lack of power. Thus, future studies should examine the role of similarity in music preferences in friendship stability using larger samples.

An unexpected, yet remarkable finding was that for adolescents with a high educational level, high overall music similarity predicted a 1.6 times higher chance of becoming mutual friends than for adolescents with a low educational level. These results indicate that for adolescents with a higher educational level, similarity in music preferences is more important in the selection of mutual friends than for adolescents with a low educational level. An explanation for this difference is that adolescents with a higher educational level had a more differentiated music taste than adolescents with a lower educational level (see also Ter Bogt, 2000), and that because of this greater variance in overall music preferences, overall music similarity may be more unique for tobe mutual friendship dyads in the former group than for to-be mutual friendship dyads in the latter group. Therefore, overall music similarity may be a more important selection criterion in mutual friendship formation for higher educated adolescents than for lower educated adolescents.

The present study is limited by the relatively low internal consistencies of the Elite and Popular/ Dance music dimensions. This could mean that the way the music preferences were grouped into dimensions is not equal to the way these are grouped in the minds of the participants, or that there are individual differences in adolescents' understanding of dimensions. Another limitation is that the current study concentrates only on best friendships. Therefore, we cannot tell anything about other types of friendships, such as second or third best friendships. Specifically, this study cannot tell if to-be best friends were newly acquainted or already knew each other, or whether unstable friends just switched from a first nominated friend to a second or third nominated friend or stopped seeing each other entirely. In addition, since no data were available on other types of friendships, results of the present study cannot tell whether music similarity plays a specific role in best friendships compared to other types of friendships. However, because first nominated mutual friendships show highest stability compared to other types of friendship (Berndt \& Keefe, 1995), one could argue that focussing on similarity effects over a one-year period in mutual best friendships is better than focussing on similarity effects in other more instable types of friendships. Nevertheless, future studies should use more measurements in time with shorter time intervals and focus on more types of (non)friendship than the mutual best friendships used in the present study. 
Finally, since the application of the Social Identity Theory by Tarrant et al. (2001) suggests that music preferences in friendship groups may affect adolescent music preferences, future studies should examine similarity in music preferences in adolescent friendship groups over time.

In summary, the present study provides strong evidence for specific music similarity and overall music similarity in Dutch early adolescent friendships. Similarity in social background does not seem to explain overall friendship similarity in music. Furthermore, the current study shows that non-mainstream music similarity and similarity in the overall patterning of music preferences both are related to friendship formation, and not to friendship stability.

\section{References}

Arnett, J. (1991). Adolescents and heavy-metal music: from the mouths of metalheads. Youth \& Society, 23, 76-98.

Bagwell, C. L., \& Coie, J. D. (2004). The best friendship of aggressive boys: Relationship quality, conflict management, and rule-breaking behavior. Journal of Experimental Child Psychology, 88, 5-24.

Bennet, A. (2001). Cultures of popular music. Buckingham: Open University Press.

Berndt, T. J., \& Keefe, K. (1995). Friends' influence on adolescents' adjustment to school. Child Development, 66, $1312-1329$.

Brown, B. B., Eicher, S. A., \& Petrie, S. (1986). The importance of peer group ("Crowd") affiliation in adolescence. Journal of Adolescence, 9, 73-96.

Byrne, D. (1971). The attraction paradigm. New York: Academic.

Christenson, P. G., \& Roberts, D. F. (1998). It's not only rock \& roll: Popular music in the lives of adolescents. Cresskill, NJ: Hampton Press.

Degirmencioglu, S. M., Urberg, K. A., Tolson, J. M., \& Richard, P. (1998). Adolescent friendship networks: Continuity and change over the school year. Merrill Palmer Quarterly, 44, 313-337.

Delsing, M. J. M. H., Ter Bogt, T., Engels, R. C. M. E., \& Meeus, W. H. J. (2007). Adolescents' music preferences: Factor structure, stability, and associations with big five personality characteristics. Journal of Research on Adolescence, 17, 467-480.

Duck, S. W., \& Craig, G. (1978). Personality similarity and development of friendship: A longitudinal study. British Journal of Social and Clinical Psychology, 17, 237-242.

Fehr, B. (2001). The life cycle of friendship. In C. Hendrick, \& S. S. Hendrick (Eds.), Close relationships: A sourcebook (pp. 71-82). Thousand Oaks, CA: Sage.

Griffon-Smith, M. E., \& Brownwell, C. A. (2003). Childhood peer relationships: Social acceptance, friendships, and peer networks. Journal of School Psychology, 41, 235-284.

Haggard, E. A. (1958). Intraclass correlation and the analysis of variance. Oxford, UK: Holt.

Knobloch, S., Vorderer, P., \& Zillmann, D. (1999). Der einfluss des musikgeschmacks auf die wahrnehmung moglicher freunde im jugendalter (The impact of music preferences on the perception of potential friends in adolescence). Zeitschrift fur Sozialpsychologie, 31, 18-30.

Kurdek, L. A., \& Krile, D. (1982). A developmental analysis of the relation between peer acceptance and both interpersonal understanding and perceived social self-comptenence. Child Development, 53, 1485-1491.

Laursen, B. (1993). The perceived impact of conflict on adolescent relationships. Merrill-Palmer Quarterly-Journal of Developmental Psychology, 39, 535-550.

Luo, S., \& Klohnen, E. C. (2005). Assortative mating and marital quality in newlyweds: A couple-centered approach. Journal of Personality and Social Psychology, 88, 304-326.

Meeus, W., Akse, J., Branje, S., Ter Bogt, T., Engels, R., Finkenauer, C., et al. (2004). Codebook conamore: Conflicts and management of relationships. Unpublished manuscript. Utrecht University, Faculty of Social Sciences.

Morry, M. M. (2005). Relationship satisfaction as a predictor of similarity ratings: A test of the attraction-similarity hypothesis. Journal of Social and Personal Relationships, 22, 561-584. 
Mounts, N. S., \& Steinberg, L. (1995). An ecological analysis of peer influence on adolescent grade point average and drug use. Developmental Psychology, 31, 915-922.

Newcomb, A. F., \& Bagwell, C. L. (1995). Children's friendship relations-a meta-analytic review. Psychological Bulletin, 117, 306-347.

Rentfrow, P. J., \& Gosling, S. D. (2003). The do re mi's of everyday life: The structure and personality correlates of music preferences. Journal of Personality and Social Psychology, 84, 1236-1256.

Rentfrow, P. J., \& Gosling, S. D. (2006). Message in a balled: The role of music preferences in interpersonal perception. Psychological Science, 17, 236-242.

Rentfrow, P. J., \& Gosling, S. D. (2007). The content and validity of music-genre stereotypes among college students. Psychology of Music, 35, 306-326.

Rozin, P., Riklis, J., \& Margolis, L. (2004). Mutual exposure or close peer relationships do not seem to foster increased similarity in food, music or television program preferences. Appetite, 42, 41-48.

Sikkema, P. (1999). Jongeren '99: Een generatie waar om gevochten wordt [Youngsters 99: A generation that has been fought for ]. Amsterdam: Inter/View*NSS.

Sikkema, P. (2005). Jongeren 2005 [Youngsters 2005]. Amsterdam: Audax Publishing/Media B.V.

Tajfel, H. (1978). Differentiation between social groups. London: Academic Press.

Tarrant, M., North, A. C., \& Hargreaves, D. J. (2001). Social categorization, self-esteem, and the estimated musical preferences of male adolescents. The Journal of Social Psychology, 141, 565-581.

Ter Bogt, T. (2000). De geschiedenis van jeugdcultuur en popmuziek [the history of youth culture and pop music]. In T. Ter Bogt, \& B. Hibbel (Eds.), Wilde jaren: Een eeuw jeugdcultuur [Wild years: A century of youth culture] (pp. 27-151). Utrecht: Lemma.

Ter Bogt, T. (2004). De smaak van bloed: Muziek en problemen van adolescenten [The taste of blood: Music and problems of adolescents]. Paper presented at the Decanensymposium, September 16, 2004. Amsterdam.

Ter Bogt, T., Raaijmakers, Q., Vollebergh, W., Van Wel, F., \& Sikkema, P. (2003). Youngsters and their musical taste: Musical styles and taste groups. Netherlands Journal of Social Sciences, 39, 35-52.

Tolson, J. M., \& Urberg, K. A. (1993). Similarity between adolescent best friends. Journal of Adolescent Research, 8, 274-288.

Urberg, K. A., Degirmencioglu, S. M., Tolson, J. M., \& Halliday-Scher, K. (2000). Adolescent social crowds: Measurement and relationship to friendships. Journal of Adolescent Research, 15, 427-445. 